\title{
Nutritional Genetics and Energy Metabolism in Human Obesity
}

\author{
Carole A. Conn • Roger A. Vaughan - William S. Garver
}

Published online: 1 June 2013

(C) Springer Science+Business Media New York 2013

\begin{abstract}
Obesity in the United States and other countries throughout the world represents a major health problem. The heritability of obesity susceptibility genes and interaction with components in the "obesogenic environment" promote positive energy balance responsible for weight gain. The molecular basis for gene-environment interactions remains undefined but evidence suggests that obesity susceptibility genes represent or influence the function of transcription factors regulated by various dietary macronutrients. The objective of this review article is to provide an update on i) the identification of obesity susceptibility genes, ii) the interaction of obesity susceptibility genes with dietary macronutrients, and iii) the metabolic pathways that have a central role in regulating energy balance. It is anticipated that increased knowledge of obesity susceptibility genes and interaction with dietary macronutrients that regulate metabolic pathways will result in more effective individual, family, and community-based preventative lifestyle intervention, in addition to targeted nutritional and medicinal therapies.
\end{abstract}

Keywords Adiposity · Diet · Energy balance .

Environment $\cdot$ Epigenetics · Fatty acids · Genetics · Obesity

C. A. Conn

Department of Individual, Family, and Community Education:

Nutrition, The University of New Mexico, Albuquerque,

NM 87131, USA

e-mail: cconn@unm.edu

R. A. Vaughan

Department of Health, Exercise, and Sports Sciences: Exercise

Science, The University of New Mexico, Albuquerque,

NM 87131, USA

e-mail: vaughanr@unm.edu

\section{W. S. Garver $(\bowtie)$}

Department of Biochemistry and Molecular Biology, School of Medicine, The University of New Mexico Health Sciences Center, Albuquerque, NM 87131, USA

e-mail: wgarver@salud.unm.edu

\section{Introduction}

The most recent National Health and Nutrition Examination Surveys (NHANES) indicate that childhood obesity in the United States has approximately doubled during the past three decades, while adolescent obesity has more than tripled during the same period of time $[1,2]$. These studies also report that although the prevalence of childhood and adolescent obesity has not changed since $2007-2008$, the prevalence of obesity among 2-5-year-olds (12.1\%), 6-11-year-olds (18\%), and 12-19-year-olds (18.4\%) remains at the highest reported levels since the establishment of NHANES. Similarly, the most recent NHANES reported that although the prevalence of adult obesity has not changed since 2003-2008, the prevalence of obesity among males (35.5\%) and females (35.8\%) remains at the highest reported levels [3].

It is generally accepted that an increased availability of inexpensive calorie-dense foods, a sedentary lifestyle, the built urban environment, and rural food deserts have a primary role in producing what has become known as an "obesogenic environment," which is primarily responsible for the current obesity epidemic [4-6]. However, until recently our knowledge concerning the role of obesity susceptibility genes in contributing to this major health problem has remained undefined. It has now become increasingly clear that individual heritability of obesity susceptibility genes and interaction with components in the obesogenic environment, particularly dietary macronutrients, such as saturated fats and refined carbohydrates, promote weight gain responsible for obesity $[7,8]$.

The objective of this review article is to provide an update on i) the identification of obesity susceptibility genes, ii) the interaction of obesity susceptibility genes with dietary macronutrients, and iii) the metabolic pathways that have a central role in regulating energy balance. It is anticipated that increased knowledge of obesity susceptibility genes and interaction with dietary macronutrients that 
regulate metabolic pathways will result in more effective individual, family, and community-based preventative lifestyle intervention, in addition to targeted nutritional and medicinal therapies.

\section{Energy Balance}

The weight gain responsible for obesity has traditionally been considered in terms of energy balance, the basic components of which include energy consumption, energy expenditure, and the storage of excess energy in the form of triacylglycerol within tissues, such as adipose [9॰]. When energy in the form of calories obtained from food and drink exceeds i) energy expenditure through energy required to maintain resting metabolic rate (RMR), ii) energy necessary for absorption and metabolism, and iii) energy expended during physical activity, a state of positive energy balance results with the storage of this energy in the form of triacylglycerol within adipose tissue. In contrast, if energy consumption is less than energy expenditure, a state of negative energy balance results characterized by the mobilization of energy from adipose tissue. Therefore, any genetic or environmental component that alters body weight must involve alterations in energy balance over a period of time [10].

\section{Heritability of Obesity and Environmental Factors}

It has been recognized for several decades that obesity is a heritable disorder. A landmark study using 250 monozygotic and 264 dizygotic twins demonstrated that familial genetics serves as a strong influence in predisposing individuals to overweight and obesity [11]. However, it also has become apparent that susceptibility genes interact with undefined environmental factors to increase adiposity and body weight, in what has formally become known as a "geneenvironment interaction" and defined as "a response or adaptation to an environmental agent, a behavior, or a change in behavior conditional on the genotype of the individual" [12]. The first study clearly demonstrating a gene-environment interaction in relation to weight gain was performed with 12 monozygotic twins who consumed a $1,000 \mathrm{kcal} /$ day surplus of calories for a period of 100 days while maintaining a sedentary lifestyle [13]. The results from this study showed a significant within twin-pair resemblance in adaptation to the excess calories ( $\geq 3$ times more variance in response between twin-pairs than within twinpairs in relation to increased body weight), suggesting that genetic susceptibility influenced excess fat storage. A more recent study has quantified the genetic and environmental influences of body mass index (BMI) and waist circumference among children living in an obesogenic environment and reported a substantial heritability for both measures of adiposity ( $77 \%$ ) along with providing a recommendation for more intensive lifestyle intervention for individuals who are genetically predisposed [14]. Together, it has been estimated from several studies that obesity susceptibility genes contribute an estimated $40-70 \%$ to variation in BMI within populations [15•].

\section{Dietary Macronutrients and Weight Gain}

The increased consumption of a high-fat diet, particularly a high-fat diet enriched with saturated fatty acids, has been found to be strongly associated with increased adiposity in overweight and obese children [16, 17]. Moreover, a recent study indicates that increased consumption of saturated fatty acids (but not plant protein, carbohydrates, or other types of fat) are highly associated with increased body weight among children at 6 and 18 months of age [18]. Consistent with these results, studies indicate that obesity susceptibility genes tend to preferentially interact with saturated fatty acids, but not monounsaturated fatty acids or polyunsaturated fatty acids, to promote weight gain $[19,20]$. More recent studies have demonstrated that a greater intake ( $\geq 2$ servings per day) of sugar-sweetened beverages (fruit punches, lemonades, and colas) interact with obesity susceptibility genes and associated with adiposity [21•]. Together, these results are consistent with saturated fatty acids and refined carbohydrates interacting with obesity susceptibility genes to promote weight gain, while diets with high protein content and low glycemic index are protective against obesity among children and adults as reported in the Diet, Obesity, and Genes (DiOGenes) randomized family-based studies [22, 23].

\section{Identification of Obesity Susceptibility Genes}

A decade (1996-2005) of intense investigation performed using candidate gene approaches and gene-linkage analysis culminated in the identification of 127 obesity susceptibility genes [24]. However, due to a general lack of power (low number of mice or participants used in these studies) and an inability to reproduce results obtained from these studies, only a small percentage of candidate genes now comprise the current list of approximately 50 validated obesity susceptibility genes identified using genome-wide association studies (GWAS). The more powerful GWAS performed during the past several years have revealed the robust association of gene variants with different measures of adiposity (body weight, BMI or class of obesity, and percent body fat) using tens of thousands of individuals [15•, 25, 26]. 
In brief, the first wave of GWAS performed using BMI as a measure of adiposity identified the FTO gene, which to date possesses the largest effect size $(\sim 1,100 \mathrm{~g} /$ risk allele) [27]. A second wave of GWAS performed using BMI as a measure of adiposity confirmed the FTO gene and identified the $M C 4 R$ gene which possesses a more moderate effect size $(\sim 650 \mathrm{~g} /$ risk allele) [28]. A third wave of GWAS performed using BMI as a measure of adiposity identified several novel obesity susceptibility genes (TMEM18, GNPDA2, SH2BI, MTCH2, KCTD15, NEGR1, ETV5, BDNF, SEC16B, FAIM1, NPC1, MAF, and PTER), which also possess moderate effects sizes ( $\sim 200-900 \mathrm{~g} /$ risk allele) [29-31]. Finally, a fourth wave of GWAS performed using BMI as a measure of adiposity identified an additional 20 novel obesity susceptibility genes (SLC39A8, PRKD1, GPRC5B, QPCTL, RBJ, TFAP2B, MAP2K5, NRXN3, LRRN6C, CADM2, FANCL, FLF35779, LRP1B, MTIF3, TMEM160, TNNI3K, ZNF608, NUDT3, PTBP2, and RPL27A) which also possess moderate effect sizes ( $200-600 \mathrm{~g} /$ risk allele) [32].

These initial GWAS performed using BMI served as a good estimate of adiposity but did not accurately reflect the overall distribution or percent body fat among individuals. Therefore, a number of GWAS have since been performed using measures of waist circumference, waist/hip ratio, and percent body fat. The first wave of GWAS performed using waist circumference and waist/hip ratio identified two novel obesity susceptibility genes (MSRA and LYPLAL1) along with four previously identified obesity susceptibility genes (FTO, MC4R, TFAP2B, and NRXN3) identified using BMI $[33,34]$. A second wave of GWAS performed using waist/hip ratio identified 13 novel obesity susceptibility genes (RSPO3, NFE2L3, VEGFA, TBX15-WARS2, GRB14, DNM3-PIGC, ITPR2-SSPN, HOXC13, LY86, ADAMTS9, ZNFR3-KREMEN1, NISCH-STAB1, and CPEB4) after adjustment for BMI [35]. A GWAS and population-based study performed using percent body fat as a measure of adiposity identified two novel obesity susceptibility genes (IRS1 and SPRY2) along with two other obesity susceptibility genes (FTO and NPC1) previously found to be associated with measures of adiposity using BMI $[36,37]$. Finally, the latest GWAS meta-analysis of a population-based discovery cohort with 33,533 individuals has reported that two novel genes (FGF21 and TANK) along with the FTO gene are associated with the total consumption of protein and carbohydrate [38].

To date, probably the best characterized human obesity susceptibility genes that interact with dietary macronutrients to promote positive energy balance represent a gene identified using a candidate gene approach followed by extensive validation with epidemiological studies and two genes identified using GWAS. These obesity susceptibility genes are the apolipoprotein A-2 (APOA2) gene, the fat mass and obesity (FTO) gene, and the Niemann-Pick C1 (NPC1) gene. The following sections will provide a brief update describing what is known concerning the APOA2, FTO, $N P C 1$ genes and interaction with a high-fat diet to promote positive energy balance responsible for obesity.

\section{APOA2 Gene}

The $A P O A 2$ gene is a member of the apolipoprotein multigene (APOA1, APOA2, and APOA4) family for which the encoded APOA2 protein primarily associated with highdensity lipoprotein (HDL) modulates activity of lipoprotein lipase to influence liver lipogenesis and adipose lipolysis [39-42]. An initial study indicated that individuals homozygous affected for the loss-of-function $A P O A 2$ variant (rs5082) had increased measures of adiposity (body weight, BMI, and waist circumference) and characterized with increased consumption of food composed of fat and protein compared with individuals homozygous normal or heterozygous for this gene variant [43]. A second study identified an association between individuals homozygous affected for the same gene variant and consumption ( $\geq 22 \mathrm{~g} /$ day) of saturated fat (but not unsaturated fat) compared with individuals homozygous normal or heterozygous for this gene variant [44••]. Finally, a third study indicated an interaction between this gene variant and consumption ( $\geq 22 \mathrm{~g} /$ day) of saturated fat (but not unsaturated fat) resulting in a $6.8 \%$ greater BMI compared with individuals homozygous normal or heterozygous from his gene variant in the same population [45].

\section{FTO Gene}

The fat mass and obesity (FTO) gene is a member of the non-heme dioxygenase family that encodes the FTO protein localized to the nucleus where it functions to catalyze demethylation of nucleic acid bases (1-methyladenine, 3methylthymine, and 3-methylcytosine) associated with single-strand DNA or RNA. An early study indicated that children (4-10 years of age) with the loss-of-function FTO gene variant (rs9939609) have an increased body weight and BMI, which also were associated with increased energy intake (but not weight of food that was consumed or resting energy expenditure), thereby suggesting a preference for energy-dense foods responsible for the weight gain [46••]. A subsequent study demonstrated that individuals homozygous affected for the FTO gene variant have increased BMI resulting from consuming increased saturated fats after adjustment for total energy consumption compared to individuals homozygous normal or heterozygous for this gene variant [47]. Similarly, another study indicated that children homozygous affected for the FTO gene variant tended to consume a greater percentage of calories from fat and possessed loss-of-control eating compared with individuals 
homozygous normal for this variant [48]. However, in contrast to these studies, a recent study comprised of five European countries (European Prospective Investigation into Cancer and Nutrition or EPIC) demonstrated that the FTO gene variant (9939609) does not interact with dietary factors (fat, protein, carbohydrates, or glycemic index) yet still associated with BMI and waist circumference [49]. Therefore, additional studies are now required to resolve whether the FTO gene variant actually interacts with dietary components, particularly saturated fatty acids, to promote weight gain responsible for obesity.

\section{NPCl Gene}

The Niemann-Pick C1 (NPC1) gene is a member of the sterol-sensing resistance-nodulation-division family which encodes the NPC1 protein primarily associated with a unique late endosome-like compartment [50,51]. Studies have demonstrated that the NPC1 protein has a central role in regulating the transport of lipoprotein-derived lipids (cholesterol and fatty acids) from late endosomes/lysosomes to other cellular compartments [52,53]. To date, studies have found that the NPCl gene variant (rs1805081) is associated with measures of extreme obesity (early-onset and morbidadult) and percent body fat [29, 36, 54]. Consistent with these results, $\mathrm{Npcl}$ heterozygous $\left(\mathrm{NpCl}^{+/-}\right)$mice characterized with decreased gene dosage are predisposed to weight gain when fed a high-fat diet (but not when fed a low-fat diet) compared with wild-type mice, consistent with a genediet interaction responsible for weight gain [55]. Moreover, a recent study indicates that the $N p c 1$ gene is downregulated by dietary fatty acids (but not dietary cholesterol) through feedback inhibition of the sterol regulatory elementbinding protein (SREBP) pathways [56 $]$. Therefore, additional studies must be performed to further characterize the $\mathrm{Npcl}$ gene in relation to positive energy balance responsible for obesity.

\section{Metabolic Pathways and Regulation of Energy Balance}

The functional integration of SREBP, peroxisome proliferator-activated receptor (PPAR), and other ligandbinding transcription factors have a central role in regulating the expression of genes responsible for macronutrient oxidation and fatty acid/triacylglycerol synthesis. The metabolic pathways involved have largely been demonstrated with the use of specific ligands for each of these transcription factors. For example, the PPAR $\alpha$ agonist class known as fibrates are prescribed clinically to decrease hyperlipidemia [57]. These agonists specifically activate PPAR $\alpha$ to increase transcription of genes involved in $\beta$-oxidation of fatty acids, thus diminishing liver production of triacylglycerol that would otherwise be packaged into very low density lipoproteins (VLDL) and secreted into the bloodstream [58]. Evidence that PPAR $\alpha$ activators increase $\beta$-oxidation of fatty acids and reduce body weight is provided by the observation that mice given fenofibrate while fed a high-fat diet for a period of 14 weeks weigh significantly less than mice fed the high-fat diet without fibrates, even though there was no difference in the calories consumed by these two groups of mice [59]. Moreover, PPAR $\alpha$ null mice become obese with age while in contrast transgenic mice with continuous upregulation of PPAR $\alpha$ are protected from obesity $[60,61]$. It is now well known that PPAR $\alpha$ is activated by diverse fatty acids and their metabolites and that omega-3 fatty acids can be prescribed clinically to lower hypertriacylglycerolemia $[58,62]$. Adiposity also may be reduced by omega- 3 fatty acids; 6 grams of dietary fat replaced by 6 grams of fish oil rich in omega- 3 fatty acids for a period of 3 weeks significantly reduced body fat mass and reduced respiratory quotient (providing evidence of enhanced $\beta$-oxidation of fats) among healthy adults [63].

The current understanding of metabolic pathways with a central role in regulating oxidation or storage of energy and the regulatory elements that respond to dietary macronutrients, mainly monosaccharides and fatty acids, are provided (Fig. 1). The transcription factors that increase expression of genes involved in fatty acid $\beta$-oxidation are part of the nuclear receptor superfamily and include $\operatorname{PPAR} \alpha$, $\operatorname{PPAR} \beta / \delta$, and retinoid X receptor (RXR) [64]. In addition, liver X receptors (LXR), carbohydrate response elementbinding protein (ChREBP), and SREBP-1c are involved in de novo lipogenesis, while PPAR $\gamma$ has a role in the differentiation of preadipocytes and mesenchymal stem cells required to mature adipocytes for the storage of excess triacylglycerol $[65,66]$. Differential tissue expression of these regulatory transcription factors mirrors the predominant metabolism of dietary macronutrients in these tissues. For example, the expression of PPAR $\alpha$ and PPAR $\beta / \delta$ in muscle is responsible for fatty acid $\beta$-oxidation in this tissue, while the expression of SREBP-1c and PPAR $\gamma$ in liver and adipocytes is responsible for the synthesis and storage of triacylglycerol in these tissues $[58,67]$.

Dietary fatty acids serve as natural ligands for PPARs which function as fatty acid sensors. PPAR $\alpha$ is activated by both saturated and unsaturated fatty acids to increase expression of genes encoding enzymes that catalyze $\beta$ oxidation of fatty acids in mitochondria and peroxisomes. Fatty acids with carbon lengths of less than 14 or greater than 20 do not serve as ligands for PPAR $\alpha$ as effectively as the more common dietary fatty acids [58]. In brief, PPAR $\alpha$ forms an obligatory dimer with RXR (which is activated by 9-cis retinoic acid) followed by this complex binding to the peroxisome proliferator receptor element (PPRE) within the promoter region of genes that encode enzymes that catalyze 


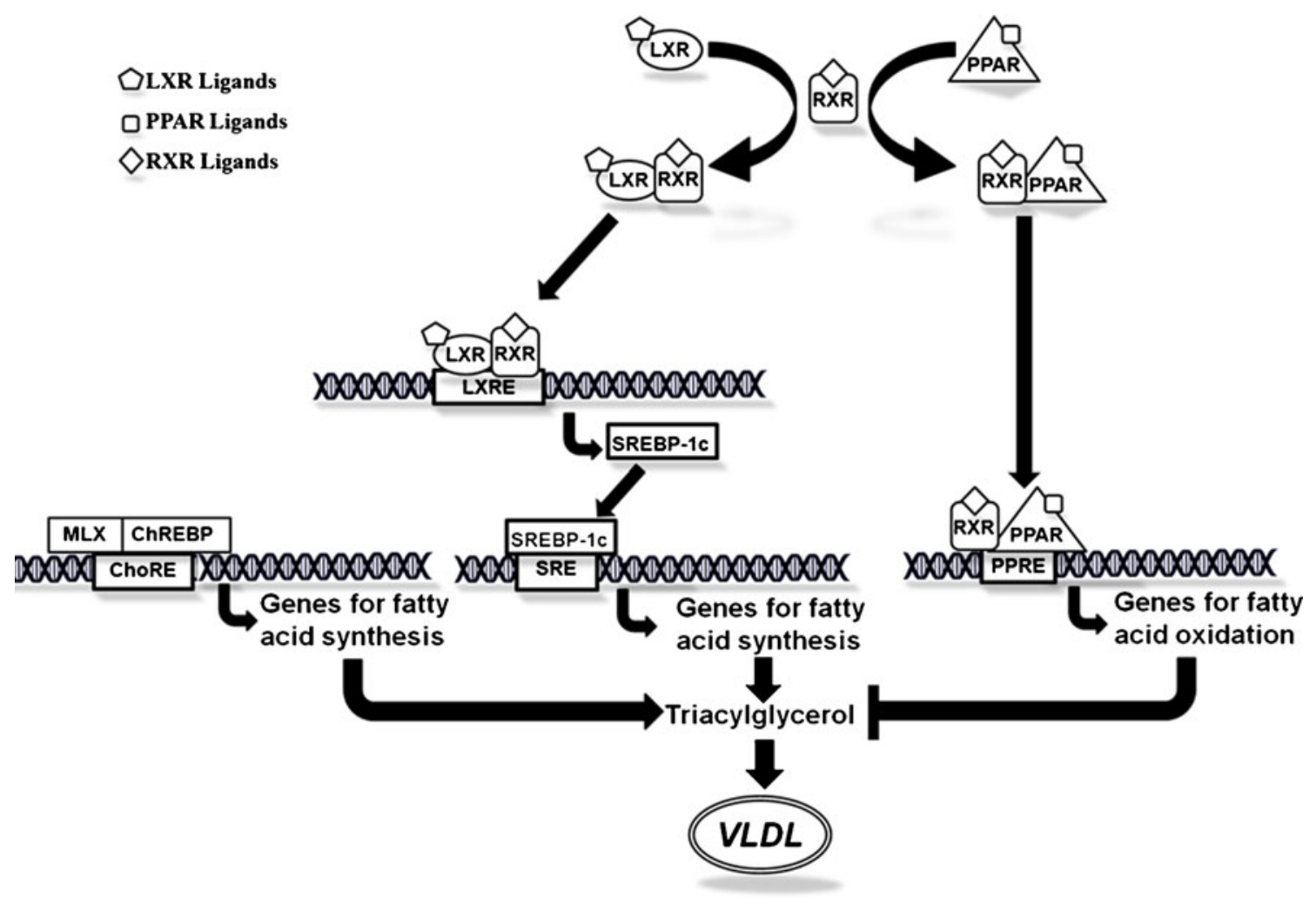

Fig. 1 Transcription factors that have a central role in maintaining energy balance and partitioning. Liver $\mathrm{X}$ receptor (LXR), retinoid $\mathrm{X}$ receptors (RXR), sterol regulatory element-binding protein-1c (SREBP-1c), peroxisome proliferator receptor element (PPRE), peroxisome proliferator-activated receptor $\alpha$ (PPAR $\alpha)$, carbohydrate response-element binding protein (ChREBP), carbohydrate response

$\beta$-oxidation of fatty acids [64]. It has also been found that activation of LXR by agonist ligands (glucose and oxysterols) prompts formation of an LXR-RXR complex and binding to LXR binding elements while at the same time inhibiting formation of the PPAR $\alpha$ RXR complex and binding to the PPREs $[68,69]$. Thus, high levels of cellular glucose promote fatty acid and triacyglycerol synthesis.

In contrast to PPAR $\alpha$ that responds to increased amounts of fatty acids to increase $\beta$-oxidation of fatty acids, the natural ligand for PPAR $\gamma$ remains undefined. The function of PPAR $\gamma$ in differentiation of adipoctyes and in insulinsensitization has been elucidated through the use of drugs known as thiazolidinediones, which serve as strong synthetic ligands [58]. Arachidonic acid and eicosapentaenoic acid are the natural fatty acid ligands that bind most readily, but elicit only weak activation, and many other small lipophilic molecules, medium chain fatty acids and eicosanoids also elicit weak activation [70-72]. Despite their efficacy in improving insulin sensitivity, thiazolidinediones have many side effects. Therefore, new partial agonists that may improve insulin sensitivity without toxic side effects are being sought [72]. Weight gain is considered one of the undesirable side effects. However, adipocyte hyperplasia induced element (ChoRE), LXR response element (LXRE,) sterol regulatory element (SRE). LXR ligands include oxysterols and glucose. PPAR ligands include fibrate drugs, thiazolidinedione drugs, saturated and unsaturated fatty acids, and phytanic acid. RXR ligands include 9-cis retinoic acid, arachidonic acid, docosahexaenoic acid, phytanic acid.

by these drugs may be one of the important insulinsensitizing mechanisms of PPAR $\gamma$ activation and weight gain from hypertrophy of adipocytes and insulin resistance may result from lower activity of PPAR $\gamma$ and other adipogenic genes [73]. Consistent with these results, a recent study has demonstrated an age-dependent (1-6 years of age) and gender-dependent (female) interaction between a PPAR $\gamma$ gene variant (Pro12Ala) and saturated fatty acids/total fat that was positively associated with BMI, waist circumference, and skinfold thickness [74••].

Dietary carbohydrates activate the ChREBP and SREBP1c transcription factors responsible for glycolysis, de novo fatty acid synthesis, and production of triacylglycerol in liver and adipocytes when excess carbohydrates are consumed $[65,75]$. As mentioned previously, physiological levels of glucose in the liver activate LXR. In addition, when there are high glucose levels, the glucose-6phosphate metabolite interacts with the low glucose inhibitory domain to prevent inhibition on the glucose response conserved element (GRACE) so that ChREBP enters the nucleus, dimerizes with max-like protein $\mathrm{X}(\mathrm{Mlx})$, and binds to the carbohydrate response element (ChoRE) in the promoter region of genes involved in fatty acid synthesis [75]. 
Genes encoding pyruvate kinase, acetyl CoA carboxylase, fatty acid synthase, stearoyl-CoA desaturase 1 , and glycerol-3-phosphate acyltransferase are all induced by both ChREBP:Mlx heterodimers and SREBP-1c that interact with response elements in their promoter regions whenever carbohydrate intake exceeds glycogen storage capacity [65, 76, 77].

Polymorphisms in these transcription factors underscore the importance of this pathway in healthy accumulation and distribution of body fat. For example, the many mutations in human PPAR $\gamma$ that result in loss or lowering of function are associated with less total body fat, lipodystrophy and/or insulin resistance [70]. Common polymorphisms in PPAR $\gamma$ explain only $1 \%$ of variation in BMI [78]. Several PPAR $\alpha$ polymorphisms have been identified [64]. At least one genetic variant (Val227Ala) was associated with lower rates of obesity, but exacerbated the amount of liver fat in patients with nonalcoholic fatty liver disease [79]. Similarly, polymorphisms in SREBP-1c and LXR have been found to be associated with overweight, obesity and/or morbid obesity [80, 81].

Another current area of research focuses on the epigenetic heritability of body weight that may occur through interaction with environmental factors, especially nutrition. Epigenetics is generally defined as the study of heritable changes in gene expression or function without modification of the DNA sequence [82]. For example, hypermethylation or hypomethylation of nucleotide bases, primarily cytosine, and histone modification through acetylation, methylation or phosphorylation is capable of modulating the transcription of genes involved in regulating energy balance [83, 84]. Moreover, nutritional status can change dietary methylation molecules during prenatal or early postnatal life and has been found to change methylation status for several genes involved in metabolic or endocrine function, changes of which are associated with childhood or adulthood adiposity $[85,86]$. Another mechanism of epigenetic adaptation occurs through microRNAs, generally derived from noncoding areas of the genome and active in suppressing gene expression. However, recently the surprising ability of microRNAs from food (rice, Chinese cabbage, wheat, and potato) that are stable to cooking and accumulate in human plasma to modify mammalian gene expression in significant ways has been published; thus plant MIR168a can decrease expression of low-density lipoprotein receptor adapter protein 1 in liver and decrease LDL removal from mouse plasma [87•]. This discovery suggests a novel type of interaction between nutrition and gene function. However, epigenetic-environment interactions in relation to obesity remains controversial, because it is difficult to determine whether epigenetic modifications causes obesity or whether obesity causes epigenetic modifications [88, 89]. As a result, whether epigenetics can be applied to clinical prevention or treatment of obesity will require further investigation [90].

\section{Conclusions}

A large number of obesity susceptibility genes have now been identified, but only a limited number were shown to interact with environmental components, such as various dietary macronutrients, to alter regulation of metabolic pathways that influence energy balance and partitioning. Although the identification of these obesity susceptibility genes has occurred in a relatively short period of time, it is suspected that defining the molecular basis for how these genes interact with environmental components to promote weight gain will take much longer. Nonetheless, it is anticipated that increased knowledge of obesity susceptibility genes and interaction with dietary macronutrients that regulate metabolic pathways will result in more effective individual, family, and communitybased preventative lifestyle intervention, in addition to targeted nutritional and medicinal therapies.

Acknowledgments This work was supported in part by the National Center for Research Resources and the National Center for Advancing Translational Sciences of the National Institutes of Health (NIH) through grant number UL1 TR000041, the Diabetes Research Center at the University of Washington through grant number P30 DK017047 as an institutional affiliate, a grant from Dedicated Health Research Funds of the University of New Mexico School of Medicine, a grant from the Tohono O'odham Nation of Southwest Arizona, and private donations for the investigation of childhood genetic and metabolic diseases.

\section{Compliance with Ethics Guidelines}

Conflict of Interest Carole A. Conn declares that she has no conflict of interest.

Roger A. Vaughan declares that he has no conflict of interest.

William S. Garver declares that he has no conflict of interest.

Human and Animal Rights and Informed Consent This article does not contain any studies with human or animal subjects performed by any of the authors.

\section{References}

Papers of particular interest, published recently, have been highlighted as:

- Of importance

-. Of major importance

1. Ogden CL, Carroll MD, Curtin LR, et al. Prevalence of high body mass index in US children and adolescents, 2007-2008. J Am Med Assoc. 2010;303:242-9.

2. Ogden CL, Carroll MD, Kit BK, et al. Prevalence of obesity and trends in body mass index among US children and adolescents, 1999-2010. J Am Med Assoc. 2012;307:483-90.

3. Flegal KM, Carroll MD, Kit BK, et al. Prevalence of obesity and trends in the distribution of body mass index among US adults, 1999-2010. J Am Med Assoc. 2012;307:491-7. 
4. Chaput JP, Klingenberg L, Astrup A, et al. Modern sedentary activities promote overconsumption of food in our current obesogenic environment. Obes Rev. 2011;12:e12-20.

5. Ferdinand O, Sen B, Rahurkar S, et al. The relationship between built environments and physical activity: A systematic review. Am J Public Health. 2012;102(10):e7-e13.

6. Yousefian A, Leighton A, Fox K, et al. Understanding the rural food environment - perspectives of low-income parents. Rural Remote Heal. 2011;11(2):1-11.

7. Bouchard C. The biological predisposition to obesity: beyond the thrifty genotype scenario. Int J Obes. 2007;31:1337-9.

8. Bouchard C. Gene-environment interactions in the etiology of obesity: Defining the fundamentals. Obesity. 2008;16:S5-S10.

9. - Hill JO, Wyatt HR, Peters JC. Energy balance and obesity. Circulation. 2012;126:126-32. This brief review article provides the latest information on energy balance and obesity.

10. Hill JO, Levine JS, Saris WHM. Energy expenditure and physical activity. In: Bray G, Bouchard C, editors. Handbook of Obesity. 2nd ed. New York: Marcel Dekker, Inc; 2003. p. 631-54.

11. Feinleib M, Garrison RJ, Fabsitz R, et al. The NHLBI twin study of cardiovascular disease risk factors: Methodology and summary of results. Am J Epidemiol. 1977;106:284-95.

12. Bouchard C. Childhood obesity: are genetic differences involved? Am J Clin Nutr. 2009;89:1494-501.

13. Bouchard C, Tremblay A, Despres JP, et al. The response to longterm overfeeding in identical twins. $\mathrm{N}$ Engl J Med. 1990;322:1477-82.

14. Wardle J, Carnell S, Haworth CMA, et al. Evidence for a strong genetic influence on childhood adiposity despite the force of the obesogenic environment. Am J Clin Nutr. 2008;87:398-404.

15. - Day FR, Loos RJR. Developments in obesity genetics in the era of genome-wide association studies. J Nutrigenet Nutrigenomics. 2011;4:222-38. This comprehensive review article provides the latest information on obesity susceptibility genes identified using GWAS

16. Aeberli I, Beljean N, Lehmann D, et al. The increase of fatty acidbinding protein $\mathrm{aP} 2$ in overweight and obese children: Interactions with dietary fat and impact on measures of subclinical inflammation. Int J Obes. 2008;32:1513-20.

17. Aeberli I, Molinari L, Spinas G, et al. Dietary intakes of fat and antioxidant vitamins are predictors of subclinical inflammation in overweight Swiss children. Am J Clin Nutr. 2006;84:748-55.

18. Lin PH, Wang Y, Grambow SC, et al. Dietary saturated fat intake is negatively associated with weight maintenance among the PREMIER participants. Obesity. 2012;20:571-5.

19. Corella D, Arnett DK, Tucker KL, et al. A high intake of saturated fatty acids strengthens the association between the fat mass and obesity-associated gene and BMI. J Nutr. 2011;141:2219-25.

20. Razquin C, Martinez JA, Martinez-Gonzalez MA, et al. A 3-year intervention with a Mediterranean diet modified the association between the rs9939609 gene variant in FTO and body weight changes. Int J Obes. 2010;34:266-72.

21. - Qi Q, Chu AY, Kang JH, et al. Sugar-sweetened beverages and genetic risk of obesity. N Eng J Med. 2012;367:1387-96. This article describes several obesity susceptibility genes that interact with sugar-sweetened beverages to promote weight gain.

22. Larsen TM, Dalskov SM, Van Baak MA, et al. Diets with high or low protein content and glycemic index for weight-loss maintenance. N Eng J Med. 2010;363:2102-13.

23. Papadaki A, Linardakis M, Larsen TM, et al. The effect of protein and glycemic index on children's body composition: The DiOGenes randominzed study. Pediatrics. 2010;126:e1143-52.

24. Rankinen T, Zuberi A, Chagnon YC, et al. The human obesity gene map: The 2005 update. Obesity. 2006;14:529-644.

25. Fernandez JR, Klimentidis YC, Dulin-Keita A, et al. Genetic influences in childhood obesity: recent progress and recommendations for experimental designs. Int J Obes. 2012;36:479-84.
26. Hofker M, Wijmenga C. A supersized list of obesity genes. Nat Genet. 2010;41:139-40.

27. Scuteri A, Sanna S, Chen W, et al. Genome-wide association scan shows genetic variants in the FTO gene are associated with obesity-related traits. PLOS Genet. 2007;3(7):e115.

28. Loos RJF, Lindgren CM, Li S, et al. Common variants near MC4R are associated with fat mass, weight and risk of obesity. Nat Genet. 2008;40(6):768-75.

29. Meyre D, Delplanque J, Chevre JC, et al. Genome-wide association study for early-onset and morbid adult obesity identifies three new risk loci in European populations. Nat Genet. 2009;41:157-9.

30. Thorleifsson G, Walters GB, Gudbjartsson DF, et al. Genome-wide association yields new sequence variants at seven loci that associate with measures of obesity. Nat Genet. 2009;41(1):18-24.

31. Willer CJ, Speliotes EK, Loos RJF, et al. Six new loci associated with body mass index highlight a neuronal influence on body weight regulation. Nat Genet. 2009;41(1).

32. Speliotes EK, Willer CJ, Berndt SI, et al. Association analyses of 249,796 individuals reveal 18 new loci associated with body mass index. Nat Genet. 2010;42:937-48.

33. Heard-Costa NL, Zillikens MC, Monda KL, et al. NRXN3 is a novel locus for waist circumference: A genome-wide association study from the CHARGE consortium. PLOS Genet. 2009;5(6):e10000539.

34. Lindgren CM, Heid IM, Randall JC, et al. Genome-wide association scan meta-analysis identifies three loci influencing adiposity and fat distribution. PLOS Genet. 2009;5(6):e1000508.

35. Heid IM, Jackson AU, Randall JC, et al. Meta-analysis identifies 13 new loci associated with waist-hip ratio and reveals sexual dimorphism in the genetic basis of fat distribution. Nat Genet. 2010;42(11):949-60.

36. den Hoed M, Luan J, Langenberg C, et al. Evaluation of common genetic variants identified by GWAS for early onset and morbid obesity in population-based samples. Int J Obes. 2012;34:1-6.

37. Kilpelainen TO, Zillikens MC, Stancakova A, et al. Genetic variation near IRS1 associates with reduced adiposity and an impaired metabolic profile. Nat Genet. 2011;43:753-60.

38. Chu AY, Workalemahu T, Paynter NP, et al. Novel locus including FGF21 is associated with dietary macronutrient intake. Hum Mol Genet. 2013;[Epub ahead of print].

39. Castellani LW, Goto AM, Lusis AJ. Studies with apolipoprotein AII transgenic mice indicate a role for HDLs in adiposity and insulin resistance. Diabetes. 2001;50:643-51.

40. Castellani LW, Nguyen CN, Charugundla S, et al. Apolipoprotein AII is a regulator of very low density lipoprotein metabolism and insulin resistance. J Biol Chem. 2008;283:11633-44.

41. Ferns GAA, Shelley CS, Stocks J, et al. A DNA polymorphism of the apoprotein AII gene in hypertriglyceridaemia. Hum Genet. 1986;74:302-6

42. Warden $\mathrm{CH}$, Daluiski A, Bu X, et al. Evidence for linkage of the apolipoprotein A-II locus to plasma apolipoprotein II and free fatty acid levels in mice and humans. Proc Natl Acad Sci U S A. 1993;90:10886-90.

43. Corella D, Arnett DK, Tsai MY, et al. The $-256 \mathrm{~T}>\mathrm{C}$ polymorphism in the apolipoprotein A-II gene promoter is associated with body mass index and food intake in the genetics of lipid lowering drugs and diet network study. Clin Chem. 2007;53:1144-52.

44. •- Corella D, Peloso G, Arnett DK, et al. APOA2, dietary fat, and body mass index. Replication of a gene-diet interaction in 3 independent populations. Arch Intern Med. 2009;169:1897-906. This article provides strong evidence that an APOA2 gene variant interacts with saturated fatty acids but not unsaturated fatty acids to promote weight gain.

45. Corella D, Tai ES, Sorli JV, et al. Association between the APOA2 promoter polymorphism and body weight in Mediterranean and Asian populations: replication of a gene-saturated fat interaction. Int J Obes. 2011;35:666-75. 
46. • Cecil JE, Tavendale R, Watt P, et al. An obesity-associated FTO gene variant and increased energy intake in children. $\mathrm{N}$ Engl $\mathrm{J}$ Med. 2008;359:2558-66. This article provides the first results indicating that a FTO gene variant interacts with saturated fatty acids to promote increased energy intake in children.

47. Sonestedt E, Roos C, Gullberg B, et al. Fat and carbohydrate intake modify the association between genetic variation in the FTO genotype and obesity. Am J Clin Nutr. 2009;90:141825 .

48. Tanofsky-Kraff M, Han JC, Anandalingam K, et al. The FTO gene rs9939609 obesity-risk allele and loss of control over eating. Am J Clin Nutr. 2009;90:1483-8.

49. Vimaleswaran KS, Angguist L, Hansen RD, et al. Association between FTO variant and change in body weight and its interaction with dietary factors: The DiOGenes study. Obesity. 2012;20(8):1669-74.

50. Carstea ED, Morris JA, Coleman KG, et al. Niemann-Pick C1 disease gene: Homology to mediators of cholesterol homeostasis. Science. 1997;277(5323):228-31.

51. Davies JP, Chen FW, Ioannou YA. Transmembrane molecular pump activity of Niemann-Pick $\mathrm{C} 1$ protein. Science. 2000;290:2295-8.

52. Chen FW, Gordon RE, Ioannou YA. NPC1 late endosomes contain elevated levels of non-esterified ('free') fatty acids and an abnormally glycosylated form of the NPC2 protein. Biochem J. 2005;390:549-61.

53. Garver WS, Krishnan K, Gallagos JR, et al. Niemann-Pick C1 protein regulates cholesterol transport to the trans-Golgi network and plasma membrane caveolae. J Lipid Res. 2002;43:579-89.

54. Cotsapas C, Speliotes EK, Hatoum IJ, et al. Common body mass index-associated variants confer risk of extreme obesity. Hum Mol Genet. 2010;19:3690-1.

55. Jelinek D, Heidenreich RA, Erickson RP, et al. Decreased Npc1 gene dosage in mice is associated with weight gain. Obesity. 2009;18:1457-9.

56. - Jelinek D, Castillo JJ, Richardson LM, et al. The Niemann-Pick $\mathrm{C} 1$ gene is downregulated in livers of C57BL/6J mice by dietary fatty acids, but not dietary cholesterol, through feedback inhibition of the SREBP pathway. J Nutr. 2012;142:1935-42. This article provides evidence indicating that fatty acids alter expression of a validated obesity susceptibility gene to promote weight gain.

57. Fazio S, Linton MF. The role of fibrates in managing hyperlipidemia: Mechanisms of action and clinical efficacy. Curr Atheroscler Rep. 2004;6:148-57.

58. Kliewer SA, Xu HE, Lambert MH, et al. Peroxisome proliferatoractivated receptors: From genes to physiology. Recent Prog Horm Res. 2001;56:239-63.

59. Guerre-Millo M, Gervois P, Raspe E, et al. Peroxisome proliferator-activated receptor alpha activators improve insulin sensitivity and reduce adiposity. J Biol Chem. 2000;275:1663842.

60. Costet P, Legendre C, More J, et al. Peroxisome proliferatoractivated receptor alpha-isoform deficiency leads to progressive dyslipidemia with sexually dimorphic obesity and steatosis. J Biol Chem. 1998;273:29577-85.

61. Huang J, Jia Y, Fu T, et al. Sustained activation of PPARa by endogenous ligands increases hepatic fatty acid oxidation and prevents obesity in ob/ob mice. FASEB J. 2012;26:628-38.

62. McKenney JM, Sica D. Role of prescription omega-3 fatty acids in the treatment of hypertriglyceridemia. Pharmacotherapy. 2007;27:715-28.

63. Couet C, Delarue J, Ritz P, et al. Effect of dietary fish oil on body fat mass and basal fat oxidation in healthy adults. Int J Obes Relat Metab Disord. 1997;21:637-43.

64. Vanden Heuvel JP. Nutrigenomics and nutrigenetics of w3 polyunsaturated fatty acids. Prog Mol Biol. 2012;108:75-102.
65. Strable MS, Ntambi JM. Genetic control of de novo lipogenesis: Role in diet-induced obesity. Crit Rev Biochem Mol Biol. 2010;45:199-214.

66. Sugii S, Evans RM. Epigenetic codes of PPARg in metabolic disease. FEBS Lett. 2011;585:2121-8.

67. Loviscach M, Rehman N, Carter L, et al. Distribution of peroxisome proliferator-activated receptors (PPARs) in human skeletal muscle and adipose tissue: Relation to insulin action. Diabetologia. 2000;43:304-11.

68. Ide T, Shimano H, Yoshikawa T, et al. Cross-talk between peroxisome proliferator-activated receptor (PPAR) alpha and liver X receptor (LXR) in nutritional regulation of fatty acid metabolism. II. LXRs suppress lipid degradation gene promotors through inhibition of PPAR signaling. Mol Endocrinol. 2003;17:1255-67.

69. Mitro N, Mak PA, Vargas L, et al. The nuclear receptor LXR is a glucose sensor. Nature. 2007;445:219-23.

70. Heikkinen S, Auwerx J, Argmann CA. PPARg in human and mouse physiology. Biochim Biophys Acta. 2007;1771:9991013.

71. Liberato MV, Nascimento AS, Ayers SD, et al. Medium chain fatty acids are selective peroxisome proliferator activated receptor (PPAR) g activators and Pan-PPAR partial agonists. PLoS One. 2012; 7:e36297.

72. Penumetcha M, Santanam N. Nutraceuticals as ligands for PPARg. PPAR Res. 2012;2012:858352.

73. Dubois SG, Heilbronn LK, Smith SR, et al. Decreased expression of adipogenic genes in obese subjects with type 2 diabetes. Obesity. 2006; 14:1543-52.

74. •• Dedoussis GV, Manios Y, Kourlaba G, et al. An age-dependent diet-modified effect of the PPAR $\gamma$ Pro12Ala polymorphism in children. Metabolism. 2011;60:467-73. This article provides the first results indicating that a PPAR $\gamma$ gene variant interacts with saturated fatty acids and total fat to increase measures of childhood adiposity.

75. Poupeau A, Postic C. Cross-regulation of hepatic glucose metabolism via ChREBP and nuclear receptors. Biochim Biophys Acta. 1812;2011:995-1006.

76. Dentin R, Benhamed F, Hainault I, et al. Liver-specific inhibition of ChREBP improves hepatic steatosis and insulin resistance in ob/ ob mice. Diabetes. 2006;55:2159-70.

77. Gonzalez-Baro MR, Lewin TM, Coleman RA. Regulation of triglyceride metabolism II. Function of mitochondrial GPAT1 in the regulation of triacylglycerol biosynthesis and insulin action. Am J Physiol Gastroinstest Liver Physiol. 2006;292:G1195-9.

78. Meirhaeghe A, Amouyel P. Impact of genetic variation of PPARg in humans. Mol Genet Metab. 2004;83:93-102.

79. Chen S, Li Y, Li S, et al. A Val227Ala substitution in the peroxisome proliferator activated receptor alpha (PPAR alpha) gene associated with non-alcoholic fatty liver disease and decreased waist circumference and waist-to-hip ratio. J Gastroenterol Hepatol. 2008;23:1415-8.

80. Eberle D, Clement K, Meyre D, et al. SREBF-1 gene polymorphisms are associated with obesity and diabetes in French obesity and diabetic cohorts. Diabetes. 2004;53:2153-7.

81. Solaas K, Legry V, Retterstol K, et al. Suggestive evidence of associations between liver $\mathrm{X}$ receptor $\mathrm{b}$ polymorphisms with type 2 diabetes mellitus and obesity in three cohort studies: HUNT2 (Norway), MONICA (France) and HELENA (Europe). BMC Med Genet. 2010;11:144.

82. Bird A. Perceptions of epigenetics. Nature. 2007;447:396-8.

83. Herrera BM, Keildson S, Lindgren CM. Genetics and epigenetics of obesity. Maturitas. 2011;69:41-9.

84. Russo P, Lauria F, Siani A. Heritability of body weight: Moving beyond genetics. Nutr Metabol Cardiovasc Dis. 2010;20:691-7. 
85. Godfrey KM, Sheppard A, Gluckman PD, et al. Epigenetic gene promoter methylation at birth is associated with child's later adiposity. Diabetes. 2011;60:1534.

86. Tobi EW, Lumey LH, Talens RP, et al. DNA methylation differences after exposure to prenatal famine are common and timingand sex-specific. Hum Mol Genet. 2009;18:4046-53.

87. - Zhang L, Hou D, Chen X, et al. Exogenous plant MIR168a specifically targets mammalian LDLRAP1: evidence of crosskingdom regulation by microRNA. Cell Res. 2012;22:107-26.
This article was the first to document that microRNAs from food can alter mammalian gene expression.

88. Martin DI, Cropley JE, Suter CM. Epigenetics in disease: Leader or follower? Epigenetics. 2011;6:843-8.

89. Youngson NA, Morris MJ. What obesity research tells us about epigenetic mechanisms. Phil Trans R Soc B. 2012;368:20110337.

90. Franks PW, Ling C. Epigenetics and obesity: The devel is in the details. BMC Med. 2010;8:88. 